\title{
Computer Mediated Communication in E- Marketing of Indonesia University Education
}

\author{
Heni Nuraeni Zaenudin \\ Universitas Pendidikan Indonesia \\ Bandung, Indonesia \\ heni.nuraeni@upi.edu
}

\begin{abstract}
The interaction between the communicator (the seller) and the communicant (the consumer) is represented in the form of textually message. Non- verbal message constitues facial expression, gesture, and voice intonation. The emotion symbols found in the textual message are usually used to complete textually verbal message. The new media used as the medium of e- marketing activity are Line, Instagram, Shoppee, twitter. The information and data are collected through a face- to- face interview and social media. The intensively social media interview is conducted with the purpose to investigate the interaction that uses computer mediated communication goes in depth. The aims of article the interaction look like in relation to the emergence of computer mediated communications in emarketing. Computer mediated communication helps some people with verbal limitation, such as lack of confidence to meet new people, lack of ability to use language properly and etc.

Keywords: Computer Mediated Communication, E- Marketing, New Media, Cybersociety
\end{abstract}

\section{INTRODUCTION}

A rapid development of technology had brought social change in society. A hundred year ago, the popularity of printed media influenced the way information was shared. To obtain any information (i.e. especially which was in relation to business), most of the people had to pay for the column. Firstly, mass communication development was realis by its circular characteristic. On this occasion, the information distribution did not only focus on its special characteristic as a printed one but also it applied audio- visual equipment.

Firstly, mass communication development was realis by its circular characteristic. On this occasion, the information distribution did not only focus on its special characteristic as a printed one but also it applied audio- visual equipment. Secondly, the media development was realis by its interactive characteristic. Some of the people called this development as "New media". The term "new" was originally inspired by media's characteristics (i.e. it was circular as well as interactive).

Secondly, the media development was realized by its interactive characteristic. Some of the people called this development as "New media". The term "new" was originally inspired by media's characteristics (i.e. it was circular as well as interactive).

In the past, if communicators wanted to get involved in a broadcasting institution, they had to join a certain media company. However, communicators in the new media era, who wanted to advertise their product, could only utilize media that had been combined with the Internet. Epistemologically speaking, "New media" is defined as an individual who has potential to be a producer for his/ her own broadcasting content published in his/her own media.

In new media era, a communicator was able to produce broadcasting contents freely only if they had an access to the Internet as well potential to understand technology. Now, let's discuss the relation of media and developed countries. A developed country refers to a country producing communication technology. The USA is one of the countries in which most of the population documented as producer of new media. For an illustration, Mark Zuckenberg is the creator of the popular social media, called Facebook while is the inventor of Youtube.

The popularity of new media in Indonesia makes many people who are running business to advertise their products through social media or website. The facilities provided by the Internet are not only employed by some of the biggest companies but also the smaller ones, even individual. It happens because the Internet does not confine to time and space.

The informants, named Dinda Larisa, Arnita, Elvin, Nurmalasari, Fitria and Armina Bionita, said that they had run e-marketing since they were in junior and senior high schools. Interacting undergoes stages of metamorphosis; in special since some social media came into exist such as Facebook, Twitter, Path, Instagram, Shoop, line, BBM, and etc. social media contribute to enlarging interaction not only across cities but also provinces and even countries.

Communication technology change the way the seller and consumer communicate and interact. Media are considered as the result of human's creation; in which human being create media with the purpose to facilitate them in doing their 
activities without confining to time and space. Computer Mediated Communication is considered as the extension of human need [1].

\section{RESEARCH METHODOLOGY}

This study selects eleven students of Indonesia University of Education, who have conducted e- marketing business at least for two years, as the participants. This study is conducted from January to August, 2016. The information and data are collected through a face- to- face interview and social media. The intensively social media interview is conducted with the purpose to investigate the interaction that uses computer mediated communication goes in depth.

This present study employs qualitative method with some of the theories and models related to computer mediated communication. The earlier definition of computer mediated communication is Computer Mediated Communication (CMC) is a process of human communications via computer, involving people, situated in particular context, engaging in processes to shape media for a variety of purposes [2], [3].

This study- besides using interview and participants to collect the data- also uses some references adapted from books or international journals which have the relevant focus of the study. Literature reviews employed in this study are: Aa [4] Computer mediated communication in adults with highfunctioning autism spectrum disorders and controls research in autism disorder. The development of synchronous text-based computer mediated communication with an intelligent diagnosis tool applied soft computing [5]. Getting real naturalistic methodology for using smartphone to collect mediated communication [6]. Computer mediated focus group networked environment [7]. Introduction: Socioliguistics and computer mediated communication [8]. Communication Technology and Society: Audience Adoption and Uses [9]. Effect of synchronrus computer mediated communication and face to face interaction on speaking skill development on Iranian learner [10]. The role of emotion in computer mediated communication: a review [11]. Computer Mediated Communication: a vehicle for learning [1]. Computer mediated communication in adultscentri with and without a history of specific language impairment (SLI) [12]. Just Click Like : CMC Responses Compliment [13]. Emotive Communication Online : A Context Analysis CMC Cues [14].

The objectives of the study are: academically, this study can contribute to the theoretical development and studies on communication, especially focusing on computer mediated communication, and practically, this study is used as a reference of the future studies on the effectiveness of communication conducted through in e-marketing in communication- major students of Indonesia University of Education.

\section{RESULTS AND DISCUSSION}

\section{A. The Form of Interaction of Computer Mediated Communication in E Marketing}

The interview with Armina, Nurmalasari and Artin shows that to overcome the limitations of text message in describing a product, the seller is suggested to use social media (e.g. Line, Instagram, Shoppe, twitter) containing audio- visual element. The facility helps the seller describe a real illustration of the offered product. In addition, the facility helps the consumer figure out the detail of the offered product such as the colour, shape, and size, even the advantages.

The seller realis that the consumer has a right to see the product before the transaction starts. Therefore, a visual display should be able to represent their product. Dinda Larisa, Armina, Artin state that to produce an interesting and artistic display of their product, they hire a photographer and model. They decide to do so because they want to produce a visually interesting picture of their product that can draw the future consumer's attention.

The characteristic of Computer mediated communication is the concept of presence [15]. This concept illustrates the psychological condition of the communicator and communicant that has been considered as the real identity. Despite the virtual interaction, the seller and consumer believe that their interest in a product is not influenced by the limitations such as regional distance, culture, value, identity, characteristic, and etc. A virtually identity (avatar) refers to the characteristic that does not need either to be discussed or argued. According to some participants, for example Elvin, he says that each of the seller and consumer in e- marketing business receives the presence concept as they get involved in the interaction. The goal of the interaction is not to argue identity but describe how the seller can sale their product as many as possible and the consumer can buy the product as their expectation.

The interesting data, according to the researchers, are the interview results that show identity is considered as an unimportant thing. From the first interaction, the seller rarely asks the consumer of his/ her identity. An e- marketing seller does need the consumer's identity. The seller will need the consumer's identity when s(he) wants to send the product.

It refers to a condition in which the seller and the consumer obtain experience that is relevant to symbols found in the converged media (android, smartphone, gadget with the Internet connection). To put it in another word, every participant who gets involved in e- marketing activity is considered as an individual who is familiar with a virtually 
interaction. The participant, who gets involved in e- marketing, certainly knows how to interact through social media- e.g. how to use social media technically and the ethic of using social media.

The society who employs the converged media should be the one who is able to use technology or even the one who is able to create technology. In using technology, the first thing that is needed to be considered is to download the necessary application as well as look for members as many as possible. Thus, the future consumer can receive the information of the product

\section{B. Computer mediated communication unify individuals in the social interaction in E Marketing}

According to a participant named Artin, who is running an e- marketing activity "This is Matte", states that the strategy used is the marketing strategy of SFS (shout for shout). The first strategy is to promote e- marketing product from one individual to one another. The second strategy is to use celebrity endorsement (i.e. advertising to some celebrities who the number of followers in instagram). The third strategy is to attend an online event. The real thing that This Is Matte has done to attract their consumer is to hold a contest called Gonna Shine.

According to another participant, called Elvin, who has run a business for three years, he shares information of his product through Instagram or Twitter. Yet, to keep in touch with this consumer intensely he prefers using Line. He promotes his product through various social media with the expectation that his consumer can obtain detail information of his product. In addition, the seller can easily influence and persuade his/ her consumer.

Having run his business for years, the founders of e marketing learnt many things from their experience and literary reviews. According to the participants, e- marketing can effectively works at certain hours. For example, from 5 to 9 am. It results from the people' habits to keep in touch with their virtual live such as gadget, smartphone and android in the morning. Next, it starts from 12 to $1 \mathrm{pm}$; and the last, from 7 to $10 \mathrm{pm}$. At the aforementioned hours, many people check their social media accounts.

Today cyberspace is one of the things that cannot be separated from human's activity. It is impossible to imagine that an individual refuse to accept the Internet and website. It seems that every problem can be solved only by clicking the sign "search" in Google. Thousands of information and data that people need are available on the Internet.

Some of the participants, Nika and Sakinah, say that people will firstly put their attention to products that they can buy and use when they see their Instragram. Seeing the virtual display of product is happiness because the product that is being offered, compel the sense of admiration of e- marketing. Many celebrities become vendors in which they will profit from being vendors. Moreover, consumers will directly buy the product if the models of the product are their idols.

In an interaction activity (communication), users of emarketing will attempt to textually combine message with one of the additional emotion icons (emoticon). The insertedemoticon message, according to another participant named Shelin, is useful to minimalize any misunderstanding that might happen in attempt to give opinions. Communication with emoticon can replace non- verbal message. The insertedemoticon message is used to obtain the same meaning. As to our knowledge, the purpose of interaction is to obtain the same meaning. Emoticon, within computer mediated communication, tries to create a sense of face- to- face communication of cyberspace [14].

Based in the segmentation of consumers, textual language is different. The result of this study shows that the participants' consumers have differences in terms of interaction and language use. The consumers are classified into youth, adult, and a group of people using polite and slang languages. The first step that the owner of e-marketing does is to identify the origin of the observed consumers.

The sellers use different labeling in e- marketing. The participants use Indonesian title name "Kakak" for the adult and "Sis" for the youth. While for men, they use "Gan" or "Bro". A participant named Nika says that the labeling is given based on the first consumer who is involved in a conversation. The first greeting the sellers use is the introduction of the conversation and title name.

The transaction ends by giving the emoticon; most of the emoticon used is "thumb" means like. In computer mediated communication, there is polite (textual) language expressed through the emoticon. the emoticon "thumb" expresses the reward of a good service given by the sellers and also used by the consumers who are going to use online shopping service [13].

Sellers are trying to persuade their consumers to give their testimony of their product. The more symbol thumb, signaling like, the more credible the product that is being offered is. The symbol 'Like' refers to consumers' reference whether the product has many consumers or not [13].

\section{The Advantage of Establishing Communication Computer Mediated Communication}

The advantage of e- marketing is it can reach consumer widely. Communication through the Internet has the attraction and certain advantage, namely it can reach the future consumer who live inter islands in Indonesia; it also can reach people outside Indonesia. Social media accounts are not only used to look for some new friends across different countries but also to function as the media for politics, economics, culture, and business. 
From the reviewed journals, it concludes that the Internet can unify people coming from different places in the world at the same time. Thousands of virtual communities form a country called citizen. In the new media era, none of the people state that they are from 244 different countries but they will consider themselves as one nation who live with the same converged media. The characteristics of computer mediated communication are digitalis and convergence, the increase of interactivity and connectivity, mobilization of text delivery and receipt, de-location, adaptation and audience's role, and the blur of media institution [8], [11], [12], [16].

\section{CONCLUSION}

The conclusion of this study is e- marketing has a special interaction form. The interaction between the communicator (the seller) and the communicant (the consumer) is represented in the form of textually message. Non- verbal message constitues facial expression, gesture, and voice intonation. The emotion symbols found in the textual message are usually used to complete textually verbal message.

The new media used as the medium of e- marketing activity are Line, Instagram, Shoppee, twitter. The social media provide buyers acilities such as video and the other visual equipment. The message starts when the consumer sees the product virtually through the social media. The virtual medium are the factor that can determine whether the communication will be terminated by the transaction or not.

The other characteristic of computer mediated communication through e marketing is the presence concept. The interest of the seller and consumer does not only confine to regional border, identity, or individual characteristic. A virtual identity is a characteristic that is not necessary to be arguable. According to the participants, both of the seller and consumer are able to accept the presence concept.

The second conclusion is that computer mediated communication can unify individuals within e marketing activity. According to the critical culture, cyberspace is defined as domain or the extension of cultures in the converged media era. Computer mediated communication becomes a part of daily communication.

The variety of the offered social media exist to create different concentrates. Instagram and twitter are employed to share information to their followers as many as possible. However, for the purpose of holding the intense communication (i.e. among the individuals), people tend to use the other social media such as line, whats up, BBM and etc. It aims at facilitating the future consumer(s) to obtain detail information from the seller.

Comunication in internet have dimension interest and activity. The dimension are for information utility as receive information and online news, leasure or fun activity as online for pleasure or cyberstalking, communication as sending and receive message, translation as e commerce and e marketing.

The third conclusion is that, communication using computer mediated communication has many advantages. One of them is that the seller can reach their future consumer(s) widely. The social media are not only used to exchange cultural, politic, economic ideas but also business. The communication through cyberspace has replaced interpersonal communication of face- to- face communication. A physical relationship never really exists, it only takes place in online. Computer mediated communication helps some people with verbal limitation, such as lack of confidence to meet new people, lack of ability to use language properly and etc.

\section{REFERENCES}

[1] Linda D Grooms.2003 Computer Mediated Communication: A Vehicle for Learning. The International Review of Research in Open And Distributed Learning Vol 4 No 2.

[2] Hoser Bettina 2005 Analysis of Asymetric Communication Patterns in Computer Mediated Communication Envirinment Universitatsverlag Print in Demand.

[3] Herring Susan 2001 Culture Technology, Communication Global Village States University of New York Press. Albany

[4] Aa Christine et all 2015 Computer-mediated communication in adults with high-functioning autism spectrum disorders and controls research in autism disorder 23 (2015) 15-27 akses sciencedirect Chenn-Jung Huang et all. 2015 Supporting the development of synchr

[5] onous text-based computer-mediated communication with an intelligent diagnosis tool applied soft computing 39 (2015) 266-276 akses sciencedirect

[6] C.Tussell. P Kortum. C. Shepard et all 2012 Getting Real A Naturalistic Methodologi For Using Smartphone to Collect Mediated Communications. Vol 2012 hal 1-10

[7] Kathy K Franklin and Catherine Lowry. 2001. Computer Mediated Focus Group Sessions Qualitative Research Journal vol r (2) : 169-r84

[8] Jannis Androutsopoulos 2006 Introduction of Socioliguistics and Computer Mediated Communications. Journal of Socioliguistics vol 4 page 419-438

[9] Joseph B Wather 2008. Attraction To Computer Mediated Social Support. Journal of Socioliguistics page 188-153

[10] Masoud Zoghi Nader Assadi. 2013. Effect of Synchronrus Computer Mediated Communications and Face to Face Interaction on Speaking Skill Development Of Iranian EFL Learners. Internasional Journal OF Applied Linguistics and English Literature. Vol. 2 Page 5

[11] Daantje Derk et all. 2007. The Role of Emotion In Computer Mediated Communication. Journal Computer In Human Behavior page 177

[12] Kevin Darkin et all 2010 Computer Mediated Communication In Adulscentri With And Without a History of Specific Language Impairment (SLI). Journal Computer In Human Behaviour Page 176-185

[13] Carment Muiz Arevaio 2013 Just Click Like : Computer Mediated responses to Spanish Compliment Page Journal of Pragmatics page 47 67

[14] Ilona Vandergriff 2013 Emotive Communication Online : A Contextual Analysis of Computer Mediated Communication (CMC) Cues. Journal of Pragmatic page 1-12

[15] Rooksby Emma 2002 Email and Ethnics Style and Ethical Relations in Computer Mediated Communications Routledge London New York

[16] Joseph B Walther \& Kyle P.D Addario. 2001. The Impact of Emoticons on Message Interpretation in Computer Mediated Communication. Social Science Computer Review Vol19 No 3 Page 324-347 
